\title{
Risk Factors for Wound Dehiscence after Guided Bone Regeneration in Dental Implant Surgery
}

\author{
Young-Kyun Kim, Pil-Young Yun \\ Department of Oral and Maxillofacial Surgery, Section of Dentistry, Seoul National University Bundang Hospital
}

Abstract

Purpose: The purpose of this study was to evaluate risks for wound dehiscence after guided bone regeneration (GBR) in dental implant surgery.

Methods: Patients who received dental implant therapy with GBR procedure at Seoul National University Bundang Hospital (Seongnam, Korea) from June 2004 to May 2007 were included. The clinical outcome of interest was complications related to dental implant surgery. The factors influencing wound dehiscence, classified into patient-related factors, surgery-related factors and material-related factors, were evaluated.

Results: One hundred and fifteen cases (202 implants) were included in this study. Wound dehiscence (19.1\%) was considered a major complication. The risk of wound dehiscence was higher in males than in females (odds ratio=4.279, $P=0.014$ ). In the main graft, the allogenic group had the lowest risk of wound dehiscence (odds ratio $=0.106, P=0.006$ ). Though the external connection group had a higher risk of wound dehiscence than the internal connection group (odds ratio=2.381), the difference was not significant $(P=0.100)$.

Conclusion: In this study, male gender and main graft have the highest risk of wound dehiscence. To reduce wound dehiscence after GBR, instructions on postoperative care with supplementary procedure for the protection of the wound dehiscence is recommended, especially to male patients. A main graft with a gel base can reduce the risk of wound dehiscence.

Key words: Dental implants, Guided bone regeneration, Complication, Wound dehiscence

\section{Introduction}

With the development of surgical techniques and biomaterials in the field of dentistry, dental implant is a common, reliable option for edentulous patients. In a minor bony defect like bony dehiscence or fenestration, guided bone regeneration (GBR) procedure can cover exposed implant threads after dental implant placement. Research on GBR[1-3] demonstrates successful clinical outcomes. Though GBR is safe and conservative in comparison with other aggressive bone graft techniques, potential surgical complications, such as wound dehiscence causing barrier membrane exposure, should be considered, especially for submerged implants[4]. Wound dehiscence is partially attributed to the use of a barrier membrane[5]. Clinically, wound dehiscence is troublesome, and carries a high risk of complications such as wound infections, graft loss, or implant failure[6]. Although generally concern over dental implant surgery complications 
is focused on clinical outcomes such as implant survival or grafted bone loss, dehiscence of an intraoral wound is undesirable[7,8]. Patients with wound dehiscence are nervous about food ingestion and anxious about contamination of the surgical wound. Extra care time is required to treat exposed membrane, above regular healing time. For the highly qualified dental service, it is important to be aware of risks influencing of wound dehiscence.

This study evaluated GBR clinical outcomes and estimated risks influencing wound dehiscence after GBR in dental implant surgery.

\section{Material and Methods}

The Institutional Review Board at Seoul National University Bundang Hospital (B-0808/060-102) approved this retrospective study. The patients who received dental implant therapy with GBR procedure by an oral surgeon at Seoul National University Bundang Hospital (Seongnam, Korea) from June 2004 to May 2007 were included in this study. Those patients classified as American Society of Anesthesiologist (ASA) class I or II were included. All patients who took antiplatelet agents discontinued medication for five to seven days before implant surgery. Postoperative prescriptions included cephalexin $1.0 \mathrm{~g}$ (clindamycin 300 $\mathrm{mg}$ in cases of allergy) with talniflumate $370 \mathrm{mg}$ three times per day for five days, and chlorhexine gluconate (Hexmedine; Bukwang Co., Seoul, Korea) mouth-rinse twice per day for 10 days. Sutures were removed 10 days after surgery. Routine post-operative checks were scheduled at two, four, and 12 weeks. Patients with wound dehiscence were checked twice a week, until secondary wound healing was completed, with additional chlorhexine gluconate mouth-rinses. Second-stage surgery was performed after six months of healing time.

Clinical outcomes of GBR cases, including surgical complications and failure, were evaluated in terms of patient-related factors, surgery-related factors and material-related factors. Gender, age, general health state and smoking are patient-related factors. Implant location, the number of implants and immediate implant are surgery-related factors. When simultaneous implant placement was done on the tooth-extracted site, that was designated an immediate implant. Implant system connection type, implant fixture length and diameter, membrane type and main graft in are material-related factors. The implant systems were either external hex or internal hex on the base of the abutment connection. The external hex implant systems used in this study were USII, USIII (Osstem Implant Co., Busan, Korea), and TiUnite (Nobel Biocare AB, Gothenburg, Sweden). The internal hex implant systems were GSII (Osstem Implant Co.), Implantium (Dentium Co., Yongin, Korea). Implant length was sorted as short $(\leq 10.0 \mathrm{~mm})$, standard $(>10.0 \mathrm{~mm},<13.0 \mathrm{~mm})$, or long $(\geq 13.0 \mathrm{~mm})$. Implant diameter was sorted as narrow $(\leq 3.5 \mathrm{~mm})$, standard $(>3.5$ $\mathrm{mm},<4.5 \mathrm{~mm})$, or wide $(\geq 4.5 \mathrm{~mm})$. The barrier membranes were either resorbable or non-resorbable membranes. The resorbable membranes used in this study were Biogide (Geistlich Pharma AG, Wolhusen, Switzerland), Biomesh (Samyang Co., Seoul, Korea), and Ossix (Colbar LifeScience Ltd., Herzliya, Israel). The non-resorbable membranes were Frios $^{\circledR}$ BoneShield (Frident, Mannheim, Germany) and Goretex (e-PTFE; W.L. Gore \& Associates Inc., Flagstaff, AZ, USA). Main grafts were autogenic, allogenic, and heterogenic according to the graft material occupying the major portion (over $75 \%$ of total volume of grafted material). The allogenic graft material used were Dembone (Pacific Tissue Bank, Los Angeles, CA, USA), Orthoblast ${ }^{\circledR}$ II (Integra OrthoBiologics Inc., Irvine, CA, USA), and Regenafil (Exactech Inc., Gainesville, FL, USA); and the heterogenic graft materials were BBP (OCT Inc., Cheonan, Korea), Biocera (OCT Inc.), and BioOss (Geistlich Pharma AG).

The relationships between categorical variables were analyzed by chi-square test or Fisher's exact test. To assess factors influencing wound dehiscence, multivariate logistic regression was applied with the variables that passed cut-off significance $(P<0.25)$ in the preliminary univariate analysis. Statistical analyses used PASW Statistics ver. 18.0 for Windows (IBM Co., Armonk, NY, USA). Null hypotheses of no difference were rejected if $P$-values were less than 0.05 , or equivalently, if the $95 \%$ confidence intervals of risk point estimates excluded 1.

\section{Results}

\section{Clinical outcome}

One hundred and fifteen cases (male: 61 cases, female: 
54 cases) from 99 patients (male: 52 patients, female: 47 patients) were included in this study. Two hundred and two implants (male: 113, female: 89) were placed in this study. The age range was between 25 and 77 years and the average was 52.62 (standard deviation=11.01) years.

Table 1. Summary of complications

\begin{tabular}{lrc}
\hline \multicolumn{1}{c}{ Types of complication } & Case $(\mathrm{n}=115)$ & Implant $(\mathrm{n}=202)$ \\
\hline Wound dehiscence & $22(19.1)$ & $42(20.8)$ \\
Infection & $1(0.9)$ & $3(1.5)$ \\
Numbness & $2(1.7)$ & $6(3.0)$ \\
Failure of osseo-integration & $7(6.1)$ & $8(4.0)$ \\
\hline
\end{tabular}

Values are presented as number (\%).
The types of surgical complications and occurrence are in Table 1. The commonest complication was wound dehiscence, detected in 22 cases (19.1\%). Eight implants were removed due to osseointegration failure. Two years after final prostheses, the success rate was $96.0 \%$.

\section{Factors influencing (Table 2)}

\section{1) Patient-related factors}

Seventeen of 61 cases among the males and five of 54 cases among the females developed wound dehiscence. Male patients had a significantly higher risk of wound dehiscence compared to female patients $(P=0.011)$.

There were 50 cases (88 implants) with general disease

Table 2. Risk factors for wound dehiscence

\begin{tabular}{|c|c|c|c|c|}
\hline Variable & GBR case (implants) & WD case (implants) & $\chi^{2}$ & $P$-value \\
\hline Age (yr) & & & 0.052 & 0.820 \\
\hline $25 \sim 52$ & $55(100)$ & $11(21)$ & & \\
\hline $53 \sim 78$ & $60(102)$ & $11(21)$ & & \\
\hline Gender & & & 6.412 & 0.011 \\
\hline Male & $61(113)$ & $17(33)$ & & \\
\hline Female & 54 (89) & $5(9)$ & & \\
\hline General health state & & & 1.356 & 0.244 \\
\hline ASA II & $50(88)$ & $12(21)$ & & \\
\hline ASA I & 65 (114) & $10(21)$ & & \\
\hline Smoking & & & 1.472 & 0.225 \\
\hline Smoker & $5(10)$ & $2(3)$ & & \\
\hline Non-smoker & $110(192)$ & $20(39)$ & & \\
\hline Location & & & 1.730 & 0.630 \\
\hline Anterior maxilla & $14(27)$ & $4(8)$ & & \\
\hline Posterior maxilla & $19(34)$ & $4(7)$ & & \\
\hline Anterior mandible & 7 (10) & $2(4)$ & & \\
\hline Posterior mandible & $75(131)$ & $12(23)$ & & \\
\hline Number of placed implants (flap size) & & & 1.206 & 0.752 \\
\hline 1 & $54(54)$ & $9(9)$ & & \\
\hline 2 & $39(78)$ & $7(14)$ & & \\
\hline 3 & $18(54)$ & $5(15)$ & & \\
\hline 4 & $4(16)$ & $1(4)$ & & \\
\hline Immediate implant & & & 0.000 & 0.988 \\
\hline Delayed & $89(165)$ & $17(34)$ & & \\
\hline Immediate & $26(37)$ & $5(8)$ & & \\
\hline Connection type & & & 3.738 & 0.053 \\
\hline External hex & $47(94)$ & $13(29)$ & & \\
\hline Internal hex & $68(108)$ & $9(13)$ & & \\
\hline Implant length & & & 4.830 & 0.089 \\
\hline Short & $29(64)$ & $2(7)$ & & \\
\hline Standard & $51(78)$ & $10(17)$ & & \\
\hline Long & $35(60)$ & $10(18)$ & & \\
\hline Implant diameter & & & 1.179 & 0.555 \\
\hline Narrow & $12(20)$ & $3(4)$ & & \\
\hline Standard & 72 (125) & $15(29)$ & & \\
\hline Wide & $31(57)$ & $4(9)$ & & \\
\hline Membrane types & & & 0.084 & 0.772 \\
\hline Resorbable & $97(170)$ & $19(37)$ & & \\
\hline Non-resorbable & $18(32)$ & $3(5)$ & & \\
\hline Main graft & & & 8.792 & 0.012 \\
\hline Autogenic & $19(34)$ & $6(9)$ & & \\
\hline Allogenic & $49(81)$ & $3(9)$ & & \\
\hline Heterogenic & $47(87)$ & $13(24)$ & & \\
\hline
\end{tabular}

Values are presented as number (\%).

GBR, guided bone regeneration; WD, wound dehiscence; ASA, American Society of Anesthesiologist. 
(ASA class II). Twelve cases with general disease had wound dehiscence. Ten of 65 healthy (ASA class I) cases also developed membrane exposure. There was no significant difference between groups $(P=0.244)$.

There were five smokers in this study, whose numbers were too few for analysis.

\section{2) Surgery-related factors}

The flap location could be anterior maxilla, posterior maxilla, anterior mandible, or posterior mandible. A higher risk of membrane exposure was noted with anterior maxillary flaps (28.6\%) and anterior mandibular group (28.6\%). There was no significant complication risk from flap location $(P=0.630)$.

The number of placed implants was closely related to the size of the flap. There were 22 cases in which more than three implants were placed, and wound dehiscence was reported in six such cases (27.3\%). There was no significant complication risk from implant number $(P=0.752)$.

The immediate group included cases of simultaneous implant placement at the time of tooth extraction. The immediate and delayed groups were considered different groups because additional flap tension would be expected for the primary wound closure. In this study, 17 of 89 cases in the delayed group and five of 26 cases in immediate group developed wound dehiscence. There was no significant complication risk from implant timing $(P=0.988)$.

Table 3. Univariate analysis of risk factors for wound dehiscence

\begin{tabular}{|c|c|c|c|}
\hline $\begin{array}{l}\text { Variable included in } \\
\text { logistic regression }\end{array}$ & $\begin{array}{l}\text { Odds } \\
\text { ratio }\end{array}$ & $\begin{array}{l}95 \% \text { confidence } \\
\text { interval }\end{array}$ & $P$-value \\
\hline \multicolumn{4}{|l|}{ Gender } \\
\hline Male & 3.786 & $1.290 \sim 11.116$ & 0.015 \\
\hline Female & 1.000 & & \\
\hline \multicolumn{4}{|l|}{ General health state } \\
\hline ASA II & 1.737 & $0.682 \sim 4.426$ & 0.247 \\
\hline ASA I & 1.000 & & \\
\hline \multicolumn{4}{|l|}{ Smoking } \\
\hline Smoker & 3.000 & $0.470 \sim 19.149$ & 0.245 \\
\hline Non-smoker & 1.000 & & \\
\hline \multicolumn{4}{|l|}{ Connection type } \\
\hline External hex & 2.507 & $0.970 \sim 6.474$ & 0.058 \\
\hline Internal hex & 1.000 & & \\
\hline Graft & & & 0.020 \\
\hline Autogenic & 1.000 & & \\
\hline Allogenic & 0.141 & $0.031 \sim 0.644$ & 0.011 \\
\hline Heterogenic & 0.828 & $0.260 \sim 2.641$ & 0.750 \\
\hline Implant length & & & 0.117 \\
\hline Short & 0.440 & $0.037 \sim 0.929$ & 0.185 \\
\hline Standard & 0.336 & $0.223 \sim 1.670$ & 0.610 \\
\hline Long & 1.000 & & \\
\hline
\end{tabular}

ASA, American Society of Anesthesiologist.

\section{3) Material-related factors}

From the 47 cases of external hex connection type implants, 13 cases developed wound dehiscence. Nine cases from 68 cases of internal hex connection type had membrane exposure. The risk of wound dehiscence was higher with external hex connection type $(P=0.058)$.

The highest risk of wound dehiscence $(28.6 \%)$ was observed with long implants (10 of 35 cases), no significant difference $(P=0.089)$. There was no significant complication risk from implant diameter $(P=0.555)$.

Nineteen of 97 cases (19.6\%) of resorbable and three of 18 cases $(16.7 \%)$ of non-resorbable membrane developed wound dehiscence, no difference $(P=0.772)$.

Six of 19 cases of autogenic group and 13 of 47 cases of heterogenic group developed wound dehiscence. Three of 49 cases of allogenic group showed membrane exposure. A significant complication risk was detected among groups $(P=0.012)$.

All of the graft materials in autogenic group and heterogenic group were particle type. One graft material (10 cases) in allogenic group was particle type and two graft materials (39 cases) in allogenic group were gel type. Twenty of 76 cases with particle type graft material and two of 39 cases with gel type graft material had wound dehiscence, a significant risk $(P=0.020)$.

Variables influencing wound dehiscence were evaluated by univariate logistic regression analysis (Table 3 ). The cut off $P$-value was 0.25 . Gender, general health state, smoking, connection type, implant length and main graft were included in the univariate logistic regression analysis.

The variables included in multiple logistic regression models were gender, main graft, and connection type (Table 4). A higher risk of wound dehiscence was observed in males (odds ratio=4.279, $P=0.014$ ). Allogenic grafts had the lowest risk of wound dehiscence (odds ratio=0.106, $P=0.006$ ).

Table 4. Multivariate analysis by logistic regression of risk factors for wound dehiscence

\begin{tabular}{lccc}
\hline Variable & Odds ratio & $\begin{array}{c}95 \% \text { confidence } \\
\text { interval }\end{array}$ & $P$-value \\
\hline $\begin{array}{l}\text { Gender } \\
\text { Male }\end{array}$ & 4.279 & $1.345 \sim 13.611$ & 0.014 \\
$\quad \begin{array}{l}\text { Female } \\
\text { Main graft }\end{array}$ & 1.000 & & 0.014 \\
$\quad$ Autogenic & 1.000 & & \\
$\quad \begin{array}{lll}\text { Allogenic } \\
\text { Heterogenic }\end{array}$ & 0.106 & $0.021 \sim 0.532$ & 0.006 \\
\hline
\end{tabular}




\section{Discussion}

GBR was developed in the late 1980s and early 1990s[9,10]. This predictable procedure is now widely used in implant surgery for minor intraoral bony defects. One of the most frequent surgical complications of GBR procedure is wound dehiscence. To avoid wound dehiscence, a tension-free flap approximation is important[11]. Irritation from dentures and remaining teeth can cause wound dehiscence[12]. There are many reports of wound dehiscence as complication of implant surgery[13,14]. With GBR, wound dehiscence results in barrier membrane exposure. An increased rate of wound dehiscence (30\%) was noted with barrier membrane use[15]. Re-suture is possible to manage small wound dehiscence occurring within 48 hours. However, in cases of large (more than $2.0 \mathrm{~cm}$ ) wound dehiscence occurring after more than two days, the margins of the wound should be excised before re-suture. This is problematic and frequently does not work well[4]. Usually, wound dehiscence with traumatized wound margins was treated by secondary intention. Granulation tissue initially covers the dehisced wound and epithelialization follows[16]. In this study, all cases of wound dehiscence were treated as secondary wound healing. Chlorhexine gluconate mouth-rinse was used to prevent infection. There were no intentional removals of membrane or graft material by subsequent infection.

There are several points that clinicians should consider. If membrane exposure is found, the average time for initial wound healing (one to two weeks) will be extended to six to eight weeks. More frequent exams (more than 10 dental appointments) are needed for wound checking and dressing, above the usual three to five dental appointments. An additional cost is incurred for dental treatment fee and chlorhexine gluconate mouth-rinse. To most patients, money and time for treatment poses a challenge. Furthermore, implant surgery is the first step of implant treatment. Sometimes, the occurrence of surgical complication affects the relationship between surgeon and the patient for the entire duration of treatment. Overall satisfaction with implant treatment is lowered, indirectly influencing clinical outcome.

Premature exposure of non-resorbable and resorbable membranes leads to extensive resorption of the bone graft and lack of continuity between the graft and the recipient bed[17,18]. Implants placed simultaneously with prematurely exposed barrier membranes show significantly higher crestal bone loss up to 24 months after placement compared with non-exposed membranes[19].

Interestingly, male patients had a significantly higher risk of wound dehiscence compared to female patients. A possible partial explanation includes the carelessness of male patients and higher prevalence of general disease and smoking. Though it was excluded in the final model, higher bleeding tendency contributed to additional pressure on the flap.

To protect the flap, supplementary procedures such as surgical pack and surgical splint application are recommended, especially for male patients. Postoperative instruction including warning on the wound maintenance would be helpful. Interestingly, the patients who had controlled general disease (ASA II group) had a higher risk of complications than healthy patients, although they were confirmed to have no bleeding tendency or healing problem (data not shown).

Although it is difficult to separate out smoking as a single risk for implant failure, delayed wound healing and peri-implant infection are thought to be significant in the high short term failure rate in smokers[20,21]. However, smokers in this study did not have a significantly higher risk of wound dehiscence. Two of five cases (40\%) developed wound dehiscence. The number of smokers was too small to evaluate influence of smoking on wound dehiscence in this study.

There was no difference of risk of wound dehiscence by flap location. It was difficult to find simple GBR cases from the maxillary and anterior mandibular areas in this study. A combination procedure with veneer bone graft or ridge splitting was more frequent than simple GBR in the anterior maxillary and anterior mandibular areas. Also, the sinus lift procedure was combined in the posterior maxillary area.

There was no evidence of direct connection between flap size and wound dehiscence. However, if the incision is too small and the flap size is insufficient, there would be excessive pressure on the flap increasing the risk of tearing the mucosal flap. Impinged mucosal flaps would likely undergo necrosis, delay healing, and possibly con- 
tribute to implant failure[22]. It is recommended that the flap size be sufficient to expose operating field because more wound dehiscence is expected with smaller flaps. It was interesting that the patient with one or two implant placements had a higher risk of wound dehiscence than those who received three or four implant placements in this study.

Chen et al.[23] reported that more wound dehiscence would be expected with delayed implant placement because of lack of tensile strength of the soft tissue flap[24]. It was also reported that immediate implant placement may be adversely affected by the presence of infection and lack of soft tissue closure and flap dehiscence over the extraction site[25,26]. Implant placement delayed for several weeks after tooth extraction allows time for bone regeneration at the base and periphery of the socket, thereby reducing the dimensions of the socket and avoiding the need for augmentation procedures[27]. However, the concomitant resorption of buccal bone may increase the need for augmentation bucco-lingually. An interesting observation was a lower risk of wound dehiscence and membrane exposure with delayed implant placement, regardless of the type of membrane used[28,29]. Immediate implant placement after extraction did not change clinical outcome in this study.

Tal[14] reported that the risk of wound dehiscence was higher in external hex implants. Schwarts-Arad et al.[30] reported the risk of wound complication in implants with a flat cover screw lower than with a high cover screw. Adell et al.[31] inserted the implants subcrestally aimed at the level of the external hex of the implant with the bony crest. If the implant's shoulders were inserted below the crestal bone, cortical bone support was reduced at the implant's neck. Conversely, if the level of external hex was located supracrestally, the cover screw would be located more superiorly than internal connection. It was thought that the cover screw loosening was more problematic in external hex types.

Implants longer than $13.0 \mathrm{~mm}$ led to a higher risk of wound dehiscence in this study. Usually, long implants were used for more bony deficiency cases, with intentional supraplantation to use the implant as a tenting pole.

Membrane micromotion was hypothesized to decrease the regenerative response by forming a layer of soft tissue under the membrane[6]. In the ill-fixed cases, more irritation on surrounding tissue would be expected. While not settled, a lower risk of premature membrane exposure has been reported in studies using collagen membranes[29,32]. A more advanced type of collagen membrane is available that is resistant to animal and bacterial collagenase when prematurely exposed. Although collagen barriers offer improved soft tissue response, they lacked the ability to maintain adequate defect space[33,34]. There are extensive studies on non-resorbable membrane in animals and humans[35,36]. The use of titanium mesh as a barrier maximizes graft containment and eliminates the space maintenance collapse problems associated with conventional membranes[37]. In this study, there was no difference between non-resorbable membrane and resorbable membrane for the risk of wound dehiscence.

To the best of our knowledge, there is no report that the type of graft material affects wound dehiscence. In this study, allogenous graft material was superior to heterogenic graft material as the main graft. Possibly the physical properties of graft material such as malleability, plasticity, deformability are related to lower risk. Most of the allogenous material in this study contained base or carrier. Compared to heterogenous and autogenous materials, allogenous materials are better to adapt the flap against pressure. The cases using Orthoblast ${ }^{\circledR}$ II (containing reverse thermal poloxamer as carrier) and Regenafil as a main graft had a lower risk of wound dehiscence in this study[38,39]. Gel type material was easier to manipulate and to apply than granule or particle type, and collapsible and malleable, so it might be more easily adapted against pressure induced from the surrounding tissue. It did not mean that allogenous graft material was better. The physical properties of base or carrier materials should be considered.

\section{Conclusion}

From the results, gender and main graft are the factors influencing wound dehiscence. To reduce wound dehiscence after GBR, instruction on postoperative care with supplementary procedure for the protection of the wound dehiscence is recommended for the patients, especially male patients. A main graft with a gel base helps prevent wound dehiscence. 


\section{References}

1. Dahlin C, Andersson L, Linde A. Bone augmentation at fenestrated implants by an osteopromotive membrane technique. A controlled clinical study. Clin Oral Implants Res 1991;2: $159-65$.

2. Jovanovic SA, Spiekermann H, Richter EJ. Bone regeneration around titanium dental implants in dehisced defect sites: a clinical study. Int J Oral Maxillofac Implants 1992;7:233-45.

3. Buser D, Ingimarsson S, Dula K, Lussi A, Hirt HP, Belser UC. Long-term stability of osseointegrated implants in augmented bone: a 5-year prospective study in partially edentulous patients. Int J Periodontics Restorative Dent 2002;22:109-17.

4. Sadig W, Almas K. Risk factors and management of dehiscent wounds in implant dentistry. Implant Dent 2004;13:140-7.

5. Block MS, Kent JN. Factors associated with soft- and hard-tissue compromise of endosseous implants. J Oral Maxillofac Surg 1990;48:1153-60.

6. Simion M, Baldoni M, Rossi P, Zaffe D. A comparative study of the effectiveness of e-PTFE membranes with and without early exposure during the healing period. Int J Periodontics Restorative Dent 1994;14:166-80.

7. Machtei EE. The effect of membrane exposure on the outcome of regenerative procedures in humans: a meta-analysis. J Periodontol 2001;72:512-6.

8. Chiapasco M, Zaniboni M. Clinical outcomes of GBR procedures to correct peri-implant dehiscences and fenestrations: a systematic review. Clin Oral Implants Res 2009;20 Suppl 4: $113-23$.

9. Dahlin C, Gottlow J, Linde A, Nyman S. Healing of maxillary and mandibular bone defects using a membrane technique. An experimental study in monkeys. Scand J Plast Reconstr Surg Hand Surg 1990;24:13-9.

10. Buser D, Dula K, Belser U, Hirt HP, Berthold H. Localized ridge augmentation using guided bone regeneration. 1. Surgical procedure in the maxilla. Int $\mathrm{J}$ Periodontics Restorative Dent 1993;13:29-45.

11. Zarb GA, Schmitt A. The longitudinal clinical effectiveness of osseointegrated dental implants: the Toronto study. Part III: problems and complications encountered. J Prosthet Dent 1990;64:185-94.

12. Esposito M, Hirsch J, Lekholm U, Thomsen P. Differential diagnosis and treatment strategies for biologic complications and failing oral implants: a review of the literature. Int J Oral Maxillofac Implants 1999;14:473-90.

13. Adell R, Lekholm U, Rockler B, et al. Marginal tissue reactions at osseointegrated titanium fixtures (I). A 3-year longitudinal prospective study. Int J Oral Maxillofac Surg 1986;15:39-52.

14. Tal H. Spontaneous early exposure of submerged implants: i. Classification and clinical observations. J Periodontol 1999; 70:213-9.

15. Lekovic V, Kenney EB, Weinlaender M, et al. A bone regenerative approach to alveolar ridge maintenance following tooth extraction. Report of 10 cases. J Periodontol 1997;68: 563-70.

16. Greenstein G, Cavallaro J, Romanos G, Tarnow D. Clinical recommendations for avoiding and managing surgical complications associated with implant dentistry: a review. J Periodontol
2008;79:1317-29.

17. Donos N, Kostopoulos L, Karring T. Alveolar ridge augmentation using a resorbable copolymer membrane and autogenous bone grafts. An experimental study in the rat. Clin Oral Implants Res 2002;13:203-13.

18. Donos N, Kostopoulos L, Karring T. Alveolar ridge augmentation by combining autogenous mandibular bone grafts and non-resorbable membranes. Clin Oral Implants Res 2002;13: 185-91.

19. Lorenzoni M, Pertl C, Polansky RA, Jakse N, Wegscheider WA. Evaluation of implants placed with barrier membranes. A restrospective follow-up study up to five years. Clin Oral Implants Res 2002;13:274-80.

20. Jones JK, Triplett RG. The relationship of cigarette smoking to impaired intraoral wound healing: a review of evidence and implications for patient care. J Oral Maxillofac Surg 1992; 50:237-9; discussion 239-40.

21. Mosely LH, Finseth F, Goody M. Nicotine and its effect on wound healing. Plast Reconstr Surg 1978;61:570-5.

22. Giglio JA, Laskin DM. Perioperative errors contributing to implant failure. Oral Maxillofac Surg Clin North Am 1998;10: 197-202.

23. Chen ST, Wilson TG Jr, Hämmerle $\mathrm{CH}$. Immediate or early placement of implants following tooth extraction: review of biologic basis, clinical procedures, and outcomes. Int J Oral Maxillofac Implants 2004;19 Suppl:12-25.

24. Watzek G, Haider R, Mensdorff-Pouilly N, Haas R. Immediate and delayed implantation for complete restoration of the jaw following extraction of all residual teeth: a retrospective study comparing different types of serial immediate implantation. Int J Oral Maxillofac Implants 1995;10:561-7.

25. Rosenquist B, Grenthe B. Immediate placement of implants into extraction sockets: implant survival. Int J Oral Maxillofac Implants 1996;11:205-9.

26. Grunder U, Polizzi G, Goené R, et al. A 3-year prospective multicenter follow-up report on the immediate and delayed-immediate placement of implants. Int J Oral Maxillofac Implants 1999;14:210-6.

27. Nir-Hadar O, Palmer M, Soskolne WA. Delayed immediate implants: alveolar bone changes during the healing period. Clin Oral Implants Res 1998;9:26-33.

28. Nemcovsky CE, Artzi Z. Comparative study of buccal dehiscence defects in immediate, delayed, and late maxillary implant placement with collagen membranes: clinical healing between placement and second-stage surgery. J Periodontol 2002;73:754-61.

29. Zitzmann NU, Naef R, Schärer P. Resorbable versus nonresorbable membranes in combination with Bio-Oss for guided bone regeneration. Int J Oral Maxillofac Implants 1997;12: 844-52.

30. Schwartz-Arad D, Samet N, Samet N, Mamlider A. Smoking and complications of endosseous dental implants. J Periodontol 2002;73:153-7.

31. Adell R, Lekholm U, Rockler B, Brånemark PI. A 15-year study of osseointegrated implants in the treatment of the edentulous jaw. Int J Oral Surg 1981;10:387-416.

32. Nemcovsky CE, Artzi Z. Split palatal flap. I. A surgical approach for primary soft tissue healing in ridge augmentation procedures: technique and clinical results. Int J Periodontics 
Restorative Dent 1999;19:175-81.

33. Owens KW, Yukna RA. Collagen membrane resorption in dogs: a comparative study. Implant Dent 2001;10:49-58.

34. Zhao S, Pinholt EM, Madsen JE, Donath K. Histological evaluation of different biodegradable and non-biodegradable membranes implanted subcutaneously in rats. J Craniomaxillofac Surg 2000;28:116-22.

35. Buser D, Dula K, Hirt HP, Schenk RK. Lateral ridge augmentation using autografts and barrier membranes: a clinical study with 40 partially edentulous patients. J Oral Maxillofac Surg 1996;54:420-32; discussion 432-3.

36. Mellonig JT, Nevins M. Guided bone regeneration of bone defects associated with implants: an evidence-based outcome assessment. Int J Periodontics Restorative Dent 1995;15:168-85.

37. von Arx T, Hardt N, Wallkamm B. The TIME technique: a new method for localized alveolar ridge augmentation prior to placement of dental implants. Int J Oral Maxillofac Implants 1996;11:387-94.

38. Kim YK, Yun PY, Kim SG, Kim BS, Ong JL. Evaluation of sinus bone resorption and marginal bone loss after sinus bone grafting and implant placement. Oral Surg Oral Med Oral Pathol Oral Radiol Endod 2009;107:e21-8.

39. Kim YK, Yun PY, Kim SG, Lim SC. Analysis of the healing process in sinus bone grafting using various grafting materials. Oral Surg Oral Med Oral Pathol Oral Radiol Endod 2009;107: 204-11. 